ISSN 0103-5150

Fisioter. Mov., Curitiba, v. 28, n. 1, p. 13-22, Jan./Mar. 2015

Licenciado sob uma Licença Creative Commons

DOI: http://dx.doi.org.10.1590/0103-5150.028.001.A001

\title{
Repeatability and comparison of clinical tests in children with spastic diplegia and with typical development ${ }^{1,2}$
}

\author{
Repetibilidade e comparação de testes clínicos para \\ crianças diparéticas e com desenvolvimento típico
}

\author{
Tainá Ribas Mélo ${ }^{[a] 3}$, André Luiz Félix Rodacki ${ }^{[a]}$, Ana Tereza Bittencourt Guimarães ${ }^{[b]}$, \\ Vera Lúcia Israel ${ }^{[a, c] *}$ \\ [a] Universidade Federal do Paraná, Setor de Ciências Biológicas, Departamento de Educação Física, Curitiba, PR, Brazil \\ [b] Universidade Federal do Paraná, Campus Palotina, Palotina, PR, Brazil \\ [c] Universidade Federal do Paraná, Campus Litoral, Matinhos, PR, Brazil
}

\section{Abstract}

Objective: The aims of this study were to evaluate the reliability of three range of motion tests (Straight Leg Raise, Modified Thomas, and Duncan-Ely) using photographic measurements in children with spastic diplegic cerebral palsy (SD) and with typical development (TD). Methods: A cross-sectional test-retest design was applied to compare muscle-tendon unit shortening tests between groups. Results: The tests showed reliability that ranged from good to excellent (ICC > 0.8), except for the Thomas Test for the bi-articular hip

1 Grant support: This manuscript is based on a master's thesis submitted in partial fulfillment of the requirements for a Master's degree in Physical Education in the Biological Sciences Sector of the Federal University of Paraná (Universidade Federal do Paraná), by the master's student Tainá Ribas Mélo, supervised by professor PhD Vera Lúcia Israel and professor PhD André Luiz Félix Rodacki.

2 Conflict of Interest statement: The authors declare no conflict of interest.

3 REUNI grantee.

* TRM: MSc, e-mail: ribasmelo@yahoo.com.br ALFR: PhD, e-mail: rodacki@ufpr.br ATBG: PhD, e-mail: anat@brturbo.com.br VLI: PhD, e-mail: veral.israel@gmail.com 
flexor muscle-tendon unit of the TD group (ICC $=0.7$ ). Differences between groups were found in all tests $(p<0.05)$, except when the range of motion of the bi-articular hip flexor muscles was assessed using the Thomas test $(p>0.05)$. Conclusion: Children with SD presents a smaller range of motion than the TD group. However, the Thomas Test for the bi-articular hip flexor muscles was unable to determine differences between children with spastic diplegic cerebral palsy from that with typical development.

Keywords: Diplegia. Range of motion. Photographic measurements. Clinical tests. Cerebral palsy.

\section{Resumo}

Objetivo: O objetivo do estudo foi avaliar a repetibilidade de três testes de amplitude de movimento (Elevação da perna reta, Thomas Modificado e Duncan-Ely) usando medidas realizadas por fotografia em crianças com paralisia cerebral do tipo diparesia espástica (SD) e com desenvolvimento típico (TD). Métodos: O estudo teve design transversal do tipo teste-reteste para comparar o comprimento musculotendíneo entre os grupos. Resultados: Os testes mostraram repetibilidade de boa a excelente (ICC >0,8), com exceção do teste de Thomas para os flexores biarticulares do quadril para o grupo TD (ICC $=0,7)$. Diferenças entre os grupos foram encontradas em todos os testes ( $p<0,05)$, à exceção da amplitude de movimento dos flexores biarticulares do quadril ao se utilizar o teste de Thomas ( $p>0,05)$. Conclusão: Crianças com SD apresentam menores amplitudes de movimento que as crianças do grupo TD. Entretanto, o teste de Thomas para os flexores biarticulares do quadril não foi capaz de determinar diferenças entre as crianças com diparesia espástica e as crianças com desenvolvimento típico.

Palavras-chave: Diplegia. Amplitude de movimento. Medidas fotográficas. Testes clínicos. Paralisia cerebral.

\section{Introduction}

Clinical range of motion tests are commonly used to evaluate healthy and individuals with motor neuron disorders and to plan interventions and monitor patient's progress $(1,2)$. These tests are used in children with spastic diplegia cerebral palsy (CP) and functional impairments of the lower limbs $(3,4)$ to assess their physical condition and to quantify changes over time (5). Many patients with CP show muscle-tendon unit shortening and reduced range of motion $(1,6)$, which influence postural control (7) and lower limb alignment. This condition also reduces the ability to generate large torques required to perform daily life movements $(5,8)$.

In clinical practice, muscle-tendon shortening are determined using qualitative approaches, in which a dichotomous positive/negative score is applied. Other assessments can also involve visual or goniometry analysis $(1,9)$. These tests typically rely on the judgment and experience of the examiner and may vary within and between examiners $(1,10,11$, 12,13).

Despite scant evidence of a relationship between static range of motion tests and functional gait dynamics $(14,15)$ static tests are widely used in cerebral palsy rehabilitation. Children with spastic diplegia (SD) may present lower limb muscle shortening, which are also assessed using range of motion tests. The Straight Leg Raise Test (SLR) is used to determine muscle-tendon length of the hamstrings, while the Modified Thomas and Duncan-Ely tests to determine muscle-tendon length of the hip flexor muscles $(9,14$, $16,17)$. Several subjective studies been performed to determine muscular shortening in children with spastic diplegia $(1,2,9,11,12,13)$. On the other hand, objective assessment of these tests may help to determine their reliability and provide a more precise diagnostic and evidence for rehabilitation (2).

A number of studies have demonstrated high reliability of range of motion tests when a kinematic analysis of photography is performed. The reliability of the range of motion around the hip and knee in the Straight Leg Raise Test (SLR) has been shown high (11). Although some studies have supported the idea that more objective measurements are required to reduce errors and the influence of extraneous variables in range of motion tests $(10,12,13)$, quantitative data are scarce. The paucity of quantitative information is even more difficult for children (9). 
Therefore, quantifying the repeatability of range of motion tests designed to evaluate muscle-tendon shortening in children with SD is required. Normative data for range of motion tests of healthy and SD children are not known. Thus, the aim of this study was to determine the repeatability of three muscle tendon shortening tests (Straight Leg Raise, Modified Thomas and Duncan-Ely) using photography in SD children. The results of SD and healthy children were compared.

\section{Methodology}

The study was approved by the Research Ethics Committee of the Health Sciences Sector of the Federal University of Paraná (Universidade Federal do Paraná), under case number CEP/SD: 936.061.10.06, CAAE: 0037.0.091.000-10. For all subjects of this study parents or guardian of the patients informed consent.

Sample size was established a priori, regarding a significance level of 0.05 , power of 0.80 , an effect size of 1.2 and assuming a one-tailed Gaussian distribution. A critical t-value of 1.73 , with 18 degrees of freedom, assuming a sample size of 20 , with an actual power of 0.83 was obtained.

Two groups of 10 participants were formed to represent children with spastic diplegia (SD; $n=10 ; 10.3$ \pm 1.8 years-old; $29.0 \pm 5.4 \mathrm{Kg} ; 1.3 \pm 0.1 \mathrm{~m}$; 8 girls and 2 boys) and typical development (TD; $n=10 ; 10.4 \pm 1.9$ years-old; $31.5 \pm 5.4 \mathrm{Kg} ; 1.4 \pm 0.1 \mathrm{~m}$; 4 girls and 6 boys). To be included in the study, children had to be able to walk with no assistance and to understand simple verbal instructions. Children with visual problems that impeded independent walking, suffered from moderate to severe mental disabilities or motor disorders (e.g., ataxia, athetosis and dystonia), showed orthopedic variation (e.g., a discrepancy in limb length), had received botulin toxin in the lower limbs during the previous six months (18) or phenol during the previous 36 months or had undergone surgery in the lower limbs, thorax or abdomen during the previous year were not included $(19,20)$. The information to apply the inclusion/exclusion criteria was obtained by an interview performed with children's parents before initiating the experimental procedures. The SD group was recruited from institutes and/or clinics specialized in treating motor neuron disorders. The TD group was recruited from regular elementary regular schools and formed based on the assessment of the SD group in order to obtain age-paired groups and minimize differences between groups.

A paired t-test showed no differences in age ( $\mathrm{p}=$ $0.87)$, height ( $p=0.32)$, or body mass ( $p=0.99)$ between the SD and TD groups. The experimental design can be observed in Figure 1.

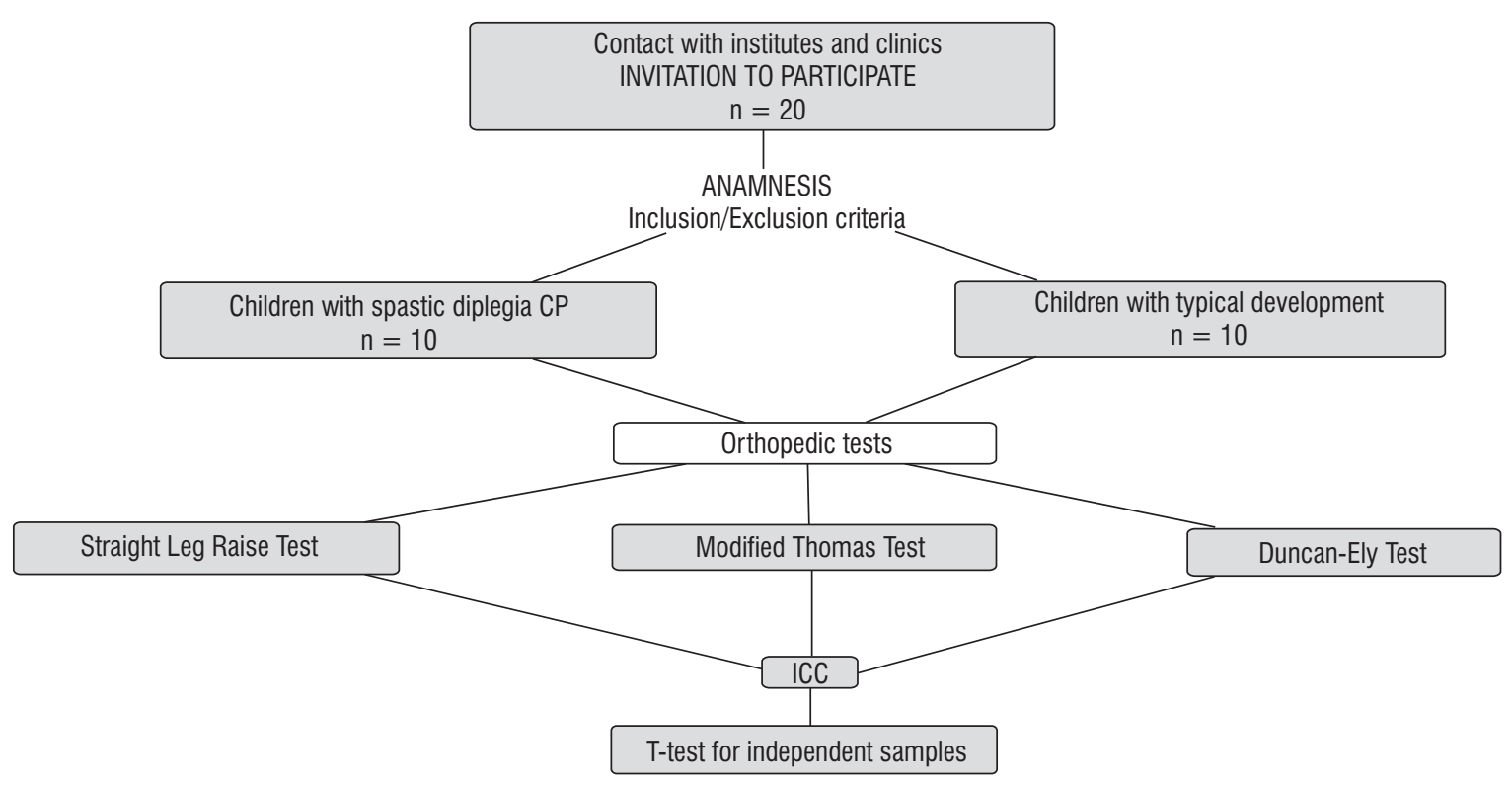

Figure 1 - Study design 
Procedures

The anthropometric assessment and the range of motion tests of the lower limbs (Straight Leg Raise, Modified Thomas, and Duncan-Ely tests) were performed during the first visit to the laboratory. The range of movement tests were performed by determining the angles of the relevant segments, which were obtained from photography images. A digital camera (Samsung, 7.2 megapixels) was placed on a tripod at a height of $0.75 \mathrm{~m}$ from a distance of $3 \mathrm{~m}$ parallel from the right sagittal plane of the subject. A set of markers $(0.9 \mathrm{~cm}$ in diameter $)$ placed at the following anatomical points were used to determine segmental position: the greater trochanter (GT), the lateral epicondyle of the femur (EF), and the fibular malleolus (MF).

The Straight Leg Raise Test (Figure 2) aimed to evaluate the range of motion of hip flexion with the knee extended passively, in order to observe the influence of the bi-articular hamstring muscles. Subjects were laid in a supine position and the lumbosacral spine was straightened by a passive bilateral hip flexion before the opposite lower limb was passively extended. Then, a single limb was raised slowly, while maintaining the knee joint extended and the foot relaxed until the subject reported discomfort. The contralateral limb remained fixed to its initial position with the aid of a Velcro strap (11). The markers on the GT and EF defined the thigh segment and allowed to determine its angle with respect to the horizontal (13). Range of motion was defined as the difference between the angle formed from the initial to the final positions. The opposite hip was not stabilized during the test because it has been shown that compensatory movements do not influence the test outcomes (2).

The Modified Thomas Test (Figure 3) aimed to evaluate the influence of the uni-articular hip flexor (UHF) and bi-articular hip flexor (BHF) muscles over the range of motion. Subjects were positioned in a supine position with the popliteal region at the edge of the exam table with the legs hanging down. The opposite leg was flexed to $125^{\circ}$ (standardized by goniometry) while keeping the lumbar curvature flat on the surface. The tested leg remained free and the movements around the hip and knee joints were determined (10). Variation between the initial and final position of the thigh with respect to the horizontal was used to determine the shortening of the UHF (Figures 3C and 3D). The shortening of the BHF
(Figures $3 \mathrm{~A}$ and $3 \mathrm{~B}$ ) was determined by the variation from the initial to final position of the knee joint angle as backward tilt of the pelvis stretches the rectus femoris muscle-tendon unit.

The Duncan-Ely Test (Figure 4) aimed to determine the spasticity and rectus femoris muscle-tendon unit shortening. The subjects were positioned a prone position and the examiner passively flexed both knees. A positive score is obtained when the pelvis is raised - as a result a rectus femoris shortening. A negative score is obtained when no pelvic compensatory changes are observed (17). Hip joint flexion angle in response to maximum passive flexion was also determined by the angle of the relevant segments (i.e., flexion until resistance is perceived). The angle of hip flexion was determined by the thigh angle variation, which was defined as the angle formed between the thigh segment and the horizontal.

Repeatability was determined by assessing three consecutive trials with intervals of approximately 12 minutes between each trial. All trials were carried out by the same examiner, who had more than 6 years of experience in such tests. The body markers were removed and replaced before trials. Subjects remained standing as markers were placed. After trials, photographs were analyzed following the methods of Sarraf, Dezan and Rodacki (10) using a commercial software (Corel Draw ${ }^{\mathrm{TM}}$ software, version 13).

\section{Data analysis}

Data were analyzed via descriptive statistics (means and standard deviations). Distribution normality was tested with Shapiro-Wilk tests, and homogeneity of variances with Levene's test. The Intraclass Correlation Coefficient (ICC) test was used with the one-way random effects (absolute agreement) model to evaluate repeatability between the three measurements. As a classification criterion, we defined ICC scores higher than 0.90 as indicating excellent reliability, ICC scores between 0.75 and 0.89 as indicating good reliability, and ICC scores of less than 0.75 as indicating poor to moderate reliability.

T-tests for independent samples were used to compare the means of the trials for each test in order to detect differences in range of motion between the two groups (SD and TD). Statistical tests were performed with Statistica ${ }^{\mathrm{TM}}$ software (StatSoft; 7.0) with a significance level of $p<0.05$. 

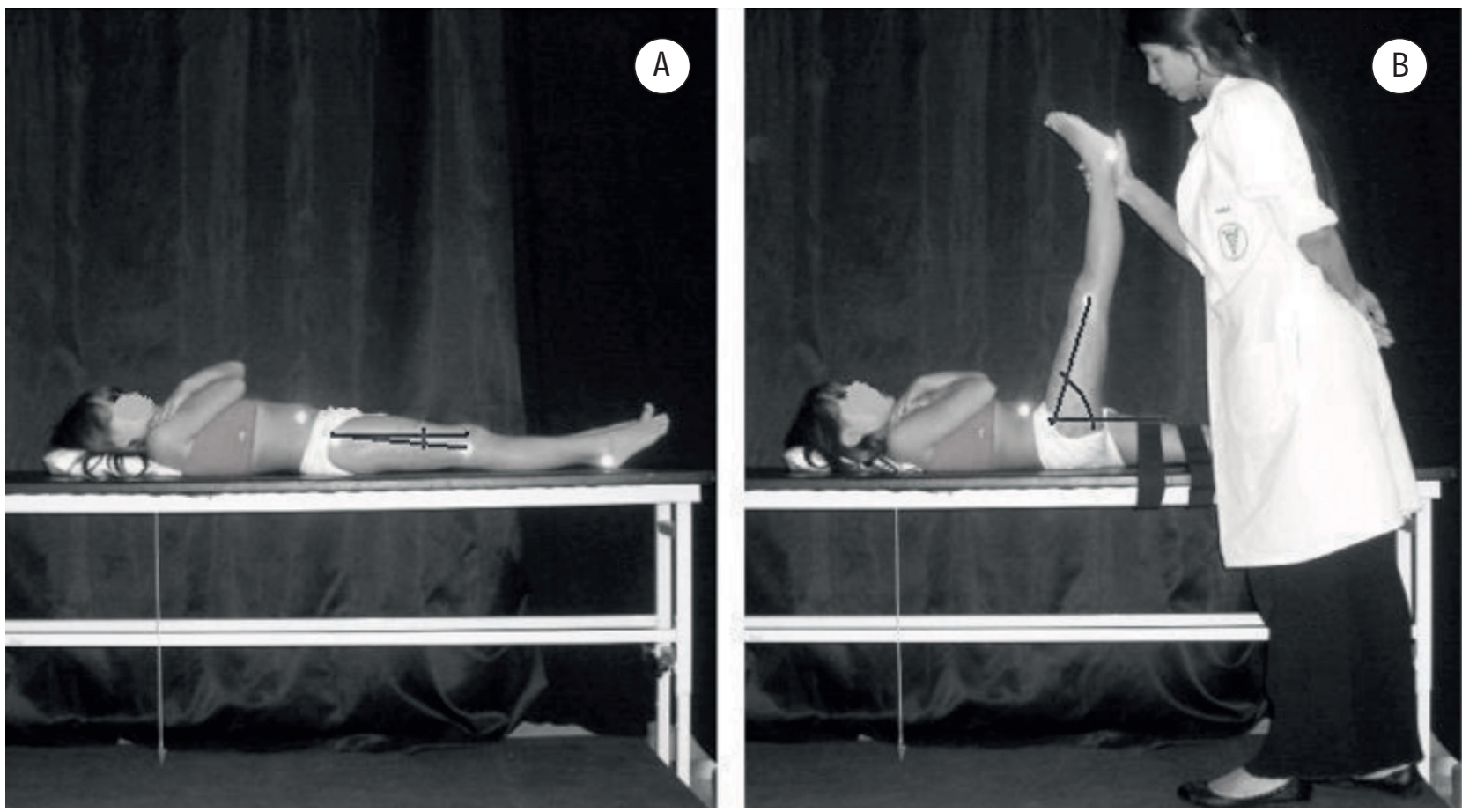

Figure 2 - Straight Leg Raise Test. A: initial position; B: final position
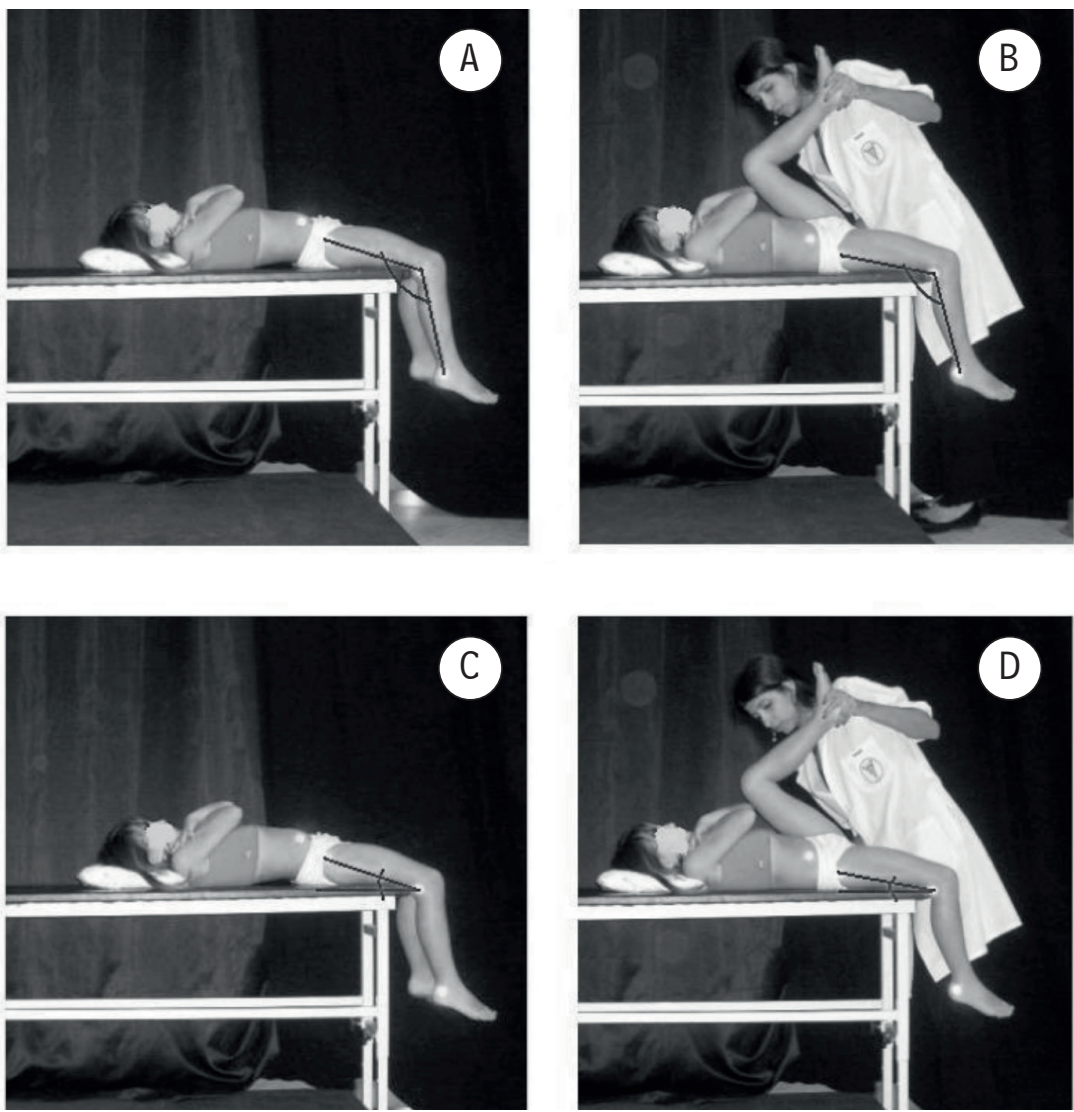

Figure 3 - Modified Thomas Test. A: initial position (Thomas BHF); B: final position (Thomas BHF); C: initial position (Thomas UHF); D: final position (Thomas UHF) 

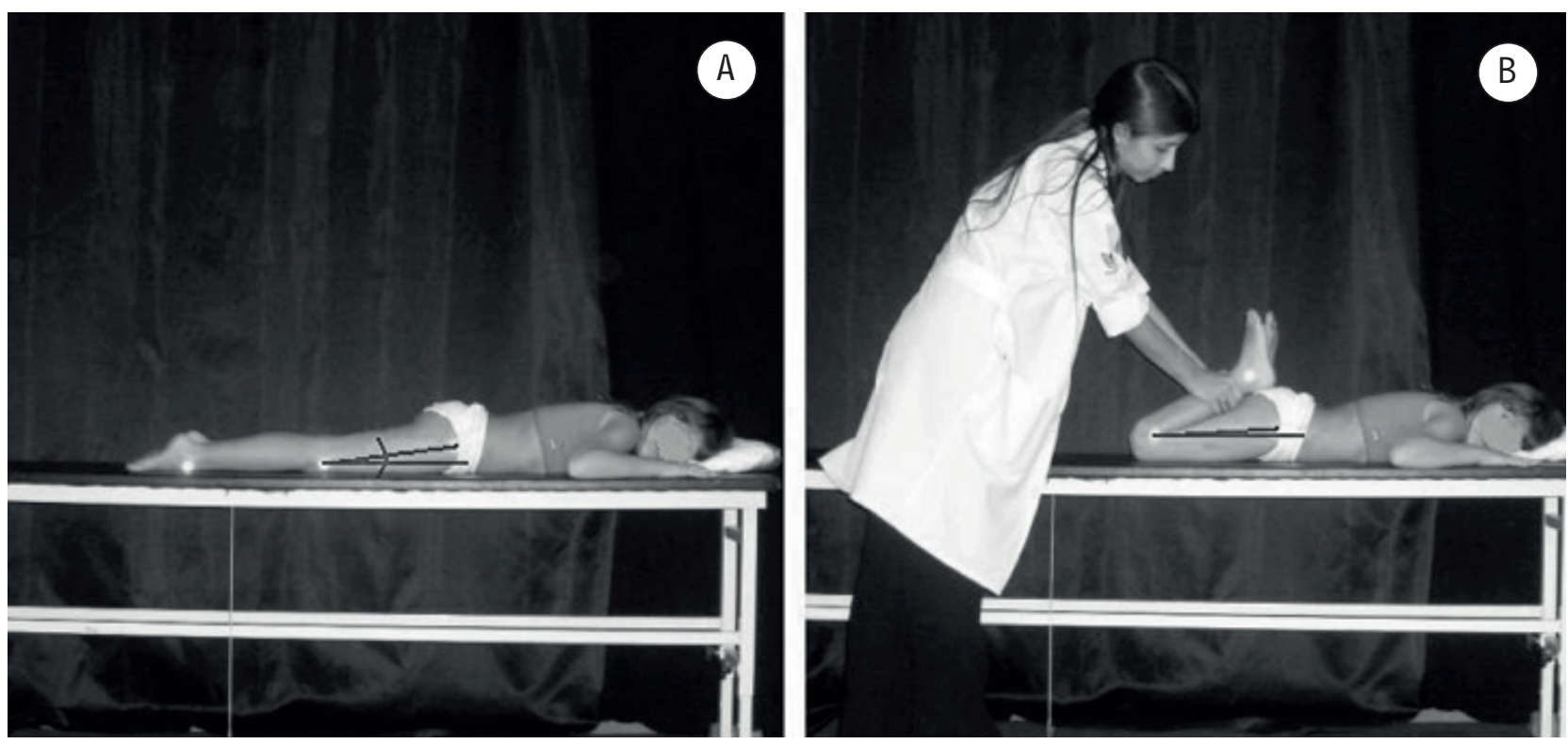

Figure 4 - Duncan-Ely test. A: initial position; B: final position

\section{Results}

Repeatability tests showed that photographic measurements did not vary significantly between trials. The mean of the range of motion tests of the SD and TD groups are provided in Table 1.

The intraclass correlation coefficients observed for the control subjects indicated that the tests were repeatable between trials. Repeatability was high for the Straight Leg Raise Test (ICC $=0.92$ ), moderate for the Thomas BHF Test (ICC $=0.69$ ), and good for the Thomas UHF and Duncan-Ely tests (ICC $=0.76$ and 0.80 , respectively). Repeatability in the SD group was good for the Straight Leg Raise, Thomas BHF, and Duncan-Ely tests (ICC $=0.82,0.80$, and 0.82, respectively), and high for the Thomas UHF Test (ICC $=0.96$ ).

The difference of the variances observed between the groups was also evident when the three trials were combined and the TD and SD groups compared. The groups differed significantly $(p<0.05)$ in the SLR, Thomas UHF, and Duncan-Ely tests. No difference between groups for the Thomas BHF Test $(p>0.05)$ was observed. Mean values of the tests are provided in Table 2.

\section{Discussion}

The literature is scarce in providing reference parameters while assessing muscle-tendon units in healthy subjects as a variety of protocols are applied. Therefore, repeatability studies are even scarcer when special populations under the influence of typical clinical and/or neurological conditions are analyzed $(1,9)$.

Patients with diplegia, require reliable muscletendon shortening tests as intervention parameters are largely guided by such exams. Thus, concerns have been raised about the repeatability of these tests in diplegic children, because muscle function tests are known to be less accurate in children than when applied in adults (9-13).

The repeatability of the SLR test ranged from good to excellent in the SD and TD groups, respectively. It is difficult to compare the reliability of the SLR test of the present study with others because most studies have used small protocol variations and/or used dichotomic measurement scales (positive $v s$. negative). The only study that used angular measurements (13) found a similar repeatability while analyzing young adults (ICC $=0.95$ ), which is an indicative that this test may not depend on subject's age or clinical characteristics. Kilgour, McNair and Sott (9) performed one of the few studies using the SLR test involving diparetic and typical development children and reported fairly close results (ICC ranged from 0.95 to 0.99 ), although measurements were obtained using a standard goniometer. The slightly small repeatability found in the SD group $($ ICC $=0.82)$ may be attributed to neurological 
influences and physical adaptations to these neural conditions $(1,2,8,15,21)$.

The SLR tests showed a greater range of motion for $\mathrm{TD}\left(71.8 \pm 8.1^{\circ}\right)$ in comparison to SD $(53.4 \pm$ $\left.8.1^{\circ}\right)$. The difference between groups $\left(18^{\circ}\right)$ was similar to that reported by Carregaro, Silva and
Coury (13) in patients with good and diminished range of motion $\left(20^{\circ}\right)$. These findings are in line with the idea that shortening of the hamstrings may prevent SD children to perform large movements around the hip joint and must be focus of clinical interventions.

Table 1 - Mean ( \pm sd) and Intraclass coefficients (ICC) of the range of motion tests of the groups of typical development $(\mathrm{TD} ; \mathrm{n}=10)$ and spastic diplegia (SD; $\mathrm{n}=10)$

\begin{tabular}{|c|c|c|c|c|c|c|}
\hline \multicolumn{7}{|c|}{ Tests } \\
\hline & & 1 & 2 & 3 & & \\
\hline & & Mean $\pm \mathrm{sd}\left({ }^{\circ}\right)$ & Mean $\pm \mathrm{sd}\left({ }^{\circ}\right)$ & Mean $\pm \mathrm{sd}\left({ }^{\circ}\right)$ & ICC & IC 95\% \\
\hline \multirow[t]{4}{*}{ TD } & SLR & $71.2 \pm 7.6$ & $72.5 \pm 8.8$ & $71.8 \pm 8.6$ & 0.92 & $0.79-0.98$ \\
\hline & Thomas BHF & $-0.6 \pm 6.5$ & $0.7 \pm 5.5$ & $2.1 \pm 6.0$ & 0.69 & $0.35-0.90$ \\
\hline & Thomas UHF & $9.6 \pm 6.0$ & $8.1 \pm 4.1$ & $8.2 \pm 5.1$ & 0.76 & $0.48-0.93$ \\
\hline & Duncan-Ely & $-1.6 \pm 3.2$ & $-0.8 \pm 3.1$ & $-1.5 \pm 2.6$ & 0.80 & $0.54-0.94$ \\
\hline \multirow[t]{4}{*}{ SD } & SLR & $53.4 \pm 9.1$ & $52.5 \pm 8.7$ & $54.3 \pm 8.3$ & 0.82 & $0.59-0.95$ \\
\hline & Thomas BHF & $4.4 \pm 14.8$ & $4.6 \pm 12.0$ & $1.5 \pm 8.8$ & 0.80 & $0.53-0.94$ \\
\hline & Thomas UHF & $23.4 \pm 9.8$ & $23.8 \pm 10.8$ & $23.8 \pm 9.7$ & 0.96 & $0.89-0.99$ \\
\hline & Duncan-Ely & $2.3 \pm 3.3$ & $1.7 \pm 2.2$ & $1.4 \pm 2.6$ & 0.82 & $0.59-0.95$ \\
\hline
\end{tabular}

Note: $\mathrm{sd}=$ standard deviation; SLR = Straight Leg Raise; BHF = bi-articular hip flexors; UHF = uni-articular hip flexor muscles.

Table 2 - Mean $( \pm s d)$ ranges of motion during the shortening tests of the spastic diplegia $(S D ; n=10)$ and typical development $(\mathrm{TD} ; \mathrm{n}=10)$

\begin{tabular}{lccc}
\hline & \multicolumn{3}{c}{ Mean \pm sd ( $\left(^{\circ}\right)$} \\
\cline { 2 - 4 } Tests & TD & SD & p \\
\hline SLR & $71.8 \pm 8.1$ & $53.4 \pm 8.1$ & $0.017^{\star}$ \\
Thomas BHF & $0.7 \pm 5.4$ & $3.5 \pm 11.2$ & 0.560 \\
Thomas UHF & $8.6 \pm 4.7$ & $23.7 \pm 9.9$ & $0.003^{\star}$ \\
Duncan-Ely & $-1.3 \pm 2.7$ & $1.8 \pm 2.6$ & 0.055 \\
\hline
\end{tabular}

Note: $s d=$ standard deviation; SLR = Straight Leg Raise; BHF = bi-articular hip flexors; UHF = uni-articular hip flexors; " ${ }^{p}$-value assuming $p<0.05$.

The Thomas Test for uni-articular flexors showed good repeatability for both groups when photographic measurements were used, as observed by others $(10,22)$. The assessment of the uni-articular hip flexors confirmed that children with diplegia have important muscle-tendon shortening in comparison to their counterparts. Indeed, these are common findings in individuals with neurological disorders, especially in children with spastic diplegia $(8,23)$, where a greater hip flexion is observed $(14,15,16$, 23). Differences between SD e TD may have occurred due to the increased tonus in response to stretching 
stimulus. Stretching stimulus applied in hypertonic muscles may cause reflex responses in which less changes in the muscle-tendon complex are obtained (24). It is plausible to speculate that the chronic muscle-tendon unit shorteningof SD children may trigger reflex responses even when small stretching stimuli are applied. In addition, it is more difficult to obtain effective acute muscle lengthening increases in shortened muscles due to passive tension effects (25). On the other hand, TD children may have experienced a stretching stimulus during the test maneuvers that resulted in a muscle-tendon complex lengthening that may have leaded to greater variability of the measurements in comparison to the SD group.

The Thomas test for the bi-articular muscles showed moderate and good reliability between the TD and SD groups, respectively. A greater variability was found when comparing the results observed between uni- and bi-articular muscles of the same test. It may be linked to the bi-articular nature of these muscles that are susceptible to the influence of two joints. The greater shortening of the uni-articular muscles changes the hip joint angle of the SD group and induces the lower leg to assume a more horizontal position. In this position, the lower leg is more prone to have an additional force due to the influence of gravity that constantly pulls the segment downwards. Thus, differences in the manipulative forces applied to stretch the bi-articular muscles may have differed between groups and explain the larger variability in the TD group. Therefore, it is possible that the Thomas test may have imposed different demands on bi-articular muscles of the SD and DT groups. This may explain contrasting variability results between SD and TD groups $(1,9,21,22,26)$.

The Duncan-Ely test has been used to quantify the shortening of the bi-articular muscles using a dichotomy scale. In this study a quantitative approach was applied by measuring the angle of the tight from the horizontal, which showed that the Duncan-Ely test presents good reliability and is also able to differentiate SD and TD groups. The SD group showed positive signs of muscle shortening (17), while the TD group presented negative shortening signs, where differences were mean significant differences that ranged from 3 to 4 degrees between groups.

The results of the Duncan-Ely test for the bi-articular muscles did not agree with those observed in the Thomas test. Differences in the posture assumed to perform the test may explain such discrepancy.
In the Thomas Test, gravitational forces may have induced to larger forces being produced around the knee joint, which may have influenced the length of the bi-articular rectus femoris muscle. In the prone position applied in the Duncan-Ely test, the effect of the gravitational forces is removed and the effects of lumbar lordosis reduced (22). Thus, the good reliability and the ability of the Duncan-Ely test to determine signs of muscle-tendon unit shortening observed in the present study is suggestive that this test must be preferred while assessing bi-articular hip joint muscle flexors shortening.

\section{Conclusions}

It was concluded that the SLR test, the Thomas Test for uni-articular hip flexor muscles and the Duncan-Ely test for bi-articular hip flexor muscles present a reliability that ranged from good to excellent when assessment is performed using a quantitative approach through photography images. These tests were able to differentiate subjects with known muscle-tendon unit shortening (diplegia) from others that were assumed to have typical development and muscle length that reflects general children population. The low ability of the Thomas test for bi-articular hip flexor muscles to discriminate children with diplegia from typical development indicated that this test may not be suitable to determine muscle-tendon unit shortening due to the position assumed during the test.

\section{Acknowledgments}

The authors thank REUNI for providing a grant in support of this master's degree research.

\section{References}

1. Bartlett MD, Wolf LS, Shurtleff DB, Stahell LT. Hip flexion contractures: a comparison of measurement methods. Arch Phys Rehabil. 1985;66(9):620-5.

2. Gajdosik RL, Rieck MA, Sullivan DK, Eightman SE. Comparison of four clinical tests for assessing hamstring muscle length. J Orthop Sports Phys Ther. 1993; 18(3):614-8. 
3. Lamonica DAC, Ferraz PMDP. Leucomalácia periventricular e diplegia espástica: implicações nas habilidades psicolingüísticas. Pró-Fono R Atual Cient. 2007;19(4):357-62.

4. Tang-Wai R, Webster RL, Shevell MI. A clinical and etiologic profile of spastic diplegia. Pediatr Neurol. 2006;34(3):212-8.

5. Rose GE, Lightbody KA, Ferguson RG, Walsh JC, Robb JE. Natural history of flexed gait in diplegic CP evaluated by gait analysis in children who have not had surgery. Gait Posture. 2010;31(3):351-4. doi: 10.1016/j. gaitpost.2009.12.006.

6. Brasileiro IC, Moreira TMM. Prevalência de alterações funcionais corpóreas em crianças com paralisia cerebral, Fortaleza, Ceará, 2006. Acta Fisiátrica. 2008; 15(1):37-41.

7. Badell-Ribera A. Cerebral palsy: postural-locomotor prognosis in spastic diplegia. Arch Phys Med Rehabil. 1985;66(9):614-9.

8. Hicks JL, Schwartz MH, Arnold AS, Delp SL. Crouched postures reduce the capacity of muscles to extend the hip and knee during the single limb stance phase of gait. J Biomech. 2008;41(5):960-7. doi: 10.1016/ j.jbiomech.2008.01.002.

9. Kilgour G, McNair P, Stott NS. Intrarater reliability of lower limb sagittal range-of-motion measures in children with spastic diplegia. Dev Med Child Neurol. 2003;45(6):391-9.

10. Sarraf TA, Dezan VH, Rodacki ALF. Diferenças entre medidas quali e quantitativas durante testes de comprimento músculo-tendíneos dos flexores do quadril uni e biarticulares. Rev Bras Fisioter. 2005; 9(5):195-201.

11. Cameron DM, Bohannon RW. Relationship between active knee extension and active straight leg raise test measurements. J Orthop Sports Phys Ther. 1993; 17(5):257-60.

12. Peeler JD, Anderson JE. Reliability limits of the modified Thomas test for assessing rectus femoris muscle flexibility about the knee joint. J Athl Train. 2008;43(5):470-6. doi: 10.4085/1062-6050-43.5.470.

13. Carregaro RL, Silva LCCB, Coury HJC. Comparação entre dois testes clínicos para avaliar a flexibilidade dos músculos posteriores da coxa. Rev Bras Fisioter. 2007;11(2):139-45. doi: 10.1590/ S1413-35552007000200009.
14. Bell KJ, Õunpuu S, Deluca PA, Romness MJ. Natural progression of gait in children with Cerebral Palsy. J Pediatr Orthop. 2002;22(5):677-82.

15. Delp SL, Arnold AS, Speers RA, Moore CA. Hamstring and psoas lengths during normal and crouch gait: implications for muscle-tendon-surgery. J Orthop Res. 1996;14(1):144-51.

16. Arnold AS, Asakawa DJ, Delp SL. Do the hamstrings and adductors contribute to excessive internal rotation of the hip in persons with cerebral palsy? Gait Posture. 2000;11(3):181-90.

17. Marks MC, Alexander J, Sutherland DH, Chambers HG. Clinical utility of the Duncan-Ely test for rectus femoris dysfunction during swing phase of gait. Dev Med Child Neurol. 2003;45(11):763-8.

18. Prosser LA, Lauer RT, VanSant AF, Barbe MF, Lee SCK. Variability and symmetry of gait in early walkers with and without bilateral cerebral palsy. Gait Posture. 2010;31(4):522-6.

19. Camargos ACR, Fontes PLB, Gontijo EG, Araújo FM, Cota K. Fisioterapia associada à toxina botulínica na diplegia espástica: um relato de caso. Fisioter Mov. 2007;20(3):17-24.

20. McDowell B, Kerr C, Kelly C, Salazar J, Cosgrove A. The validity of an existing gait classification system when applied to a representative population of children with hemiplegia. Gait Posture. 2008;28(3):442-7. doi: 10.1016/j.gaitpost.2008.02.003.

21. McDowell BC, Hewitt V, Nurse A, Weston T, Baker $R$. The variability of goniometric measurements in ambulatory children with spastic cerebral palsy. Gait Posture. 2000;12(2):114-221.

22. Glazman AM, Swenson AE, Kim H. Intrarater range of motion reliability in cerebral palsy: a comparison of assessment methods. Pediatr Phys Ther. 2008;20(4):36972. doi: 10.1097/PEP.0b013e31818b7994.

23. Lee LW, Kerrigan DC, Della Croce U. Dynamic implications of hip flexion contractures. Am J Phys Med Rehabil. 1997;76(6):502-8.

24. Fonseca ST, Ocarino JM, Silva PLP. Ajuste da rigidez muscular via sistema fuso-muscular-gama: implicações para o controle da estabilidade articular. Rev Bras Fisioter. 2004;8(3):187-95. 
Mélo TR, Rodacki ALF, Guimarães ATB, Israel VL.

25. Guissard N, Duchateau J. Neural aspects of muscle stretching. Exerc Sport Sci Rev. 2006;34(4):154-8.

26. Piriyaprasarth P, Morris ME. Psychometric properties of measurements tools for quantifying knee joint position and movement: a systematic review. Knee. 2007;14(1):2-8.

Received: 02/13/2014

Recebido: 13/02/2014

Approved: 08/20/2014

Aprovado: 20/08/2014 